\title{
Teachers in Facebook: Information Retrieval, Informal Learning or Extension of the own Social Network?
}

\author{
Livia Petti \\ Università degli Studi di Milano-Bicocca
}

\author{
Serena Triacca \\ Università Cattolica del Sacro Cuore
}

\begin{abstract}
It is well-known that learning is a field that embraces not only dedicated teaching environments, but also informal contexts: it is worth considering how much we learn from everyday situations such as exchanges with family and friends, travel and surfing the Web. This paper aims to study the Facebook pages of two Italian professional communities "Orizzonte Scuola" and "La Scuola che Funziona". It wants to understand how necessary, in our case studies, Facebook spaces are for professional development and informal learning. We adopted a quali-quantitative research methodology: 20 structured interviews were conducted to members and founders of the spaces and a communication analysis was made of the posts published on the Facebook wall. The results revealed some interesting topics such as: members' perceptions of informal learning, strengths and weaknesses of online spaces, "depth" of communication and other professional topics.
\end{abstract}

\section{Introduction}

In September 2012 Facebook reached the historic milestone of one billion members worldwide, and the average age of registered users increased, standing at 22 years compared to 19 years in 2006. In particular, Italy shows an increase in Facebook access with the 36-45 year age bracket surpassing for the first time that of 19 to 24 years olds [1].

The recent "Report on Communication" conducted by Censis/Ucsi shows another interesting fact, in reference to the Italian context: $67 \%$ of those who have access to the Internet have joined Facebook, compared to $49 \%$ in 2011 [2].

In the last decade, social media development has changed the ways in which the majority of people use the Internet. Since its creation in February 2004, Facebook has become a place of frequent everyday social interaction: continuous contact and constant updating of news and status of friends' walls, is amplified by the spread of personal media [3], which incorporate the feature of real "intermediate environments" [4], and respond to the growing need to share anywhere and anytime opinions and personal matters.

Social sciences researchers could not help but be interested in the phenomenon; they are at the forefront of an unprecedented opportunity to observe the behavior in a naturalistic setting, to test hypotheses in an unusual domain and recruit in a relatively inexpensive way participants from every part of the world.

A Washington University and University of Texas research team, with the aim to review all articles ever written about Facebook and collect them within an organic unit, have shown that despite there being rather a large amount, the literature is notably fragmented around questions, methods and points of view; Facebook is a relatively recent phenomenon and there is still uncertainty about the most effective ways to do research in this domain. The study has led to identify about 400 relevant articles from 2005 to today, sorted into five categories: descriptive analysis of Facebook users, reasons for using the social network, identity presentation, Facebook's role in social interactions, privacy and disclosure of personal information [5].

With due regard to these considerations, without any claim to achieve results neither complete nor generalized, we conducted a study with the aim to investigate whether the Facebook spaces of two Italian professional communities for teachers "Orizzonte Scuola" and "La Scuola che Funziona" could convey informal learning and thus be wheels of professional growth.

This study aims to be an extension and an completion of the previous one, conducted in the first months of 2012; in the first step [6], our research aim was to explore the perceptions of the members of the two communities regarding informal learning on the Web, with particular reference to their own online experiences and the extent to which it may be considered training. The original community is hosted on a website with a discussion forum and the other in the Ning social network.

We may speak of professional training every time when individuals become aware that they are acquiring skills, in other words, when a learning process is underway. According to Guskey and Haberman [7], training necessarily involves change in the individual. Our analysis shows that such a training process occurs for users of both online communities analyzed, despite the differences between the two settings. Certainly participation in online communities does not constitute a systematic training programme, being more related to the needs of the moment. In this sense, it could be defined as on-demand training, aimed at satisfying specific 
contingent needs, which also caters for some of the key requirements identified in our research regarding the limited amount of time available to teachers, the need for immediate on-the-job applicability of learning, the effective resolution of problems and the ease in which teachers can engage in mutual help.

\section{Theoretical background}

The recent societal changes which have given rise to the «knowledge society» [8] have also raised interest in lifelong learning.

The knowledge and skills of individuals are of key importance to the organizations they belong to. In addition to formal training programs, individuals enhance their learning in both non-formal and informal contexts.

Informal learning may take place in the course of everyday life, at work, at home or while surfing the Web and facing other users of the Net [9]. In the «network society» era [10], computer networks and social networks are going to hybridize; on line and off line networks tend to be complementary and allow individuals to manage their own social life in ever more customized ways, to a lesser extent influenced by the structured contexts of real life, such as the family and the professional [11].

Boyd \& Ellison define social network sites as «web-based services that allow individuals to construct a public or semi-public profile within a bounded system, articulate a list of other users with whom they share a connection, and view and traverse their list of connections and those made by others within the system» [12]. What makes social network sites unique is not that they allow individuals to meet strangers, but rather that they enable users to articulate and make visible their social networks.

Social networking sites are attracting with increasing frequency also groups of professionals, including teachers and trainers: in these environments, the distinctive characteristics of communities of practice [13] appear to be in the condition to express themselves, encouraging active participation and sharing of best practices.

Mindful of getting into a field still largely unexplored [14], this second step of investigation wanted to focus, primarily with interviews to the founders of the portal "Orizzonte Scuola", and the Ning group "La Scuola che Funziona":

- the reasons that have led them to create a Facebook extension;

- the differences between the original spaces and the Facebook environments;

- the existence of a publishing plan and any moderators to care for the environment.

Through interviews with members of the Facebook environment were then investigated:
- the use of the Facebook pages (the "Orizzonte Scuola" Page and "La Scuola che Funziona" Group);

- the value of the Facebook environment by the profession, from the description of an episode of meaningful learning;

- $\quad$ strengths and weaknesses of the original spaces and of the Facebook environments.

Finally, we carried out an analysis of a sample of users' wall posts of the "Orizzonte Scuola" Page and "La Scuola che Funziona" Group.

\section{Methodology}

Combined quantitative-qualitative research methodology was adopted. Structured telephone interviews [15] were conducted with members of the Facebook page "Orizzonte Scuola" and of the Facebook groups "La Scuola che Funziona". Members were contacted by the "private message" tool in Facebook. The sampling was nonprobabilistic because not all community members were equally likely to take part in the survey [16]. Those choosing to participate in the research are likely to be members with a more active interest in their online community. However this should not bias the research results, given that only active users can contribute ideas, perceptions and views regarding main the functions performed by the environment: informal learning, information sharing, and/or extension of one's own social network.

10 telephone interviews were carried out with "La Scuola che Funziona" members and 10 with "Orizzonte Scuola" members as well as being preceded by two interviews with community founders given their status as key informants [17].

Quantitative research methodology was used to make a communication analysis of posts in Facebook in order to understand what kind of communication it was, the "depth" of communication and what kind of information was posted on the "Orizzonte Scuola" page and the "La Scuola che Funziona" group. 50 posts from "La Scuola che Funziona" and 50 posts from "Orizzonte Scuola" were then analyzed and selected from the most recent posts (November 2012).

A table is used to indicate:

- date and time. To understand posting frequency;

- name and surname/gender. To understand how many users participate, if the same ones are always active and what kind of gender would be considered prevalent;

- type of message. Categorizing between: simple posts, links or images;

- message description type. Useful to understand, for each category identified above, what each message is specifically about. The "Simple post" category could be a question/help request, a 
piece information or a statement. However, the "link" category could be, specifically, a video, a news article on another site, a blog (to writers or others ), an event created on Facebook, a case/ petition, publicizing another group/page, an image or, finally, a seminar/training course;

- topic. It is interesting, in addition to categorization, to describe what exactly the topic of the post is;

- relevance. To identify off topic posts from those of pertinence;

- number of comments. Comments were counted for each post in order to understand the amount of interest that particular post had;

- number of "likes". Here, too, "likes" were counted in order to understand the amount of interest that particular post had;

- tagging. To understand whether or not authors had tagged someone in their message.

\section{Structured interviews}

20 structured telephone interviews were conducted with members of the community, 10 for each online environment preceded by two interviews with community founders.

This preliminary research was conducted with the idea of exploring the objectives and intentions that had incited founders to also create an extension of the group on Facebook. During the members' interviews, one of the goals was to find out their views of the strengths/weaknesses of the original online spaces and their Facebook extensions and whether or not informal learning could be developed on Facebook.

\subsection{Facebook space among promotion, "comfort" and lightness}

One aspect that has pushed the founders of online teaching platforms "Orizzonte Scuola" and "La Scuola che Funziona" to create in the first case a Facebook page and in the second case a group, is the awareness that this social network is now the most important and most popular on line environment in Italy as well as the rest of the world, capable of providing greater visibility and pervasiveness to news and initiatives that arise in original local communities.

"Orizzonte Scuola" operates from its Facebook page thanks to two administrators who also serve as moderators posting from time to time relevant news from the education world. Other issues are posted from statements of public figures and/or movements as well as politicians. As the founder says: "there is not a tendency of accumulating users based on themes, we believe this is much easier to manage in forums split by topic area where you create an aggregate much more solid than a Facebook page". This statement implies on the one hand the idea that the forum, according to its structure, is perhaps the most suitable instrument for reflection and communication sharing [18]. On the other hand, the communication within this page has been set by the moderators as purely one-way and is about information on when to launch issues, some politically motivated, involving the school world in order to inform users.

With "La Scuola che Funziona", the Facebook group has the main function of promoting the activities of the original nucleus born in Ning. In addition, Facebook group members post news about the school world or issues that, according to the founder, "are dealt with very lightly and due to the fact that they slip down the list a couple of days after posting, finding them can be difficult." Here also the theme of Facebook's post structure returns which by its nature is immediate, spontaneous and quick almost as a synchronous chat - [19] and it doesn't lend itself to reflection. In this group the founder leaves the user to decide to write and propose issues, unlike the "Orizzonte Scuola" page where it is possible to display separately the information posted by admin from that posted by members. Registered among the strengths of the Facebook environment are ease of use and "comfort": "you can access Facebook with your smartphone, which is more convenient!". Underlined among the weaknesses is time - Social Networks are also seen as places that "waste" a lot of time - and the habit that users have is not to search information on the Web, but to expect to receive it in on Facebook.

It is noted in both spaces the perception that members are on average younger than those on the original on line spaces, they are often not the same people and finally, prefer to join only Facebook because they already have an account and should not create one ad hoc (latter point is especially true for the on line environment "La Scuola che Funziona").

\subsection{Facebook space among sharing information, social relevance and "fast"}

20 structured interviews were conducted with members of Facebook spaces "Orizzonte Scuola" and "La Scuola che Funziona" and revealed some interesting findings that we will show below. Of the 20 respondents, 13 claim to be enrolled in the "official" spaces, while 7 are not; "being involved in just one community is challenging enough, let alone two! Surfing the internet can become a job within a job." From these words, it appears that, when deciding to attend any online space, you need plenty of time.

Regarding the issue of reading/writing, only 3 of the 20 respondents stated that they had submitted posts, 7 claim to have sometimes commented and 10 
say they have only ever read the messages. This assertion is confirmed also in the words of those who simply read, "the ones who write are always the same." Even reading them is fast; "I read quickly if there are any updates on my smartphone, I don't read everything, only what I find interesting." Just one interviewee acknowledges the fitting function the Facebook group is meant to have with the original space (in "La Scuola che Funziona")": "I need the Facebook space to remind the group members in Ning about important appointments".

Some of the strengths of the online Facebook space are revealed as follows:

- $\quad$ speed and ease with which you can access and share information, supported by the fact that the instrument allows you, even with a smartphone, to stay connected;

- social relevance. Facebook being one of the most popular social networks in the world, allowing users to expand their relationships networks in the context of now, where our knowledge "is often stored in People" [19];

- emotional dimension. Reading the comments makes it possible to find people who have similar thoughts to their own, share ideas and support each other;

- personal visibility. Facebook allows this through advertisements of one's own blog or proposed reading of scientific production or with the proposition of a seminar to give visibility to their individuality. According to Rivoltella, [20] the logic is about «identity Performance». Facebook users are characterized by a name and a surname and very few people use a nickname;

- all-in-one. Facebook allows you to see what is new in your network (social network of close friends) and also has a space for group/professional pages "it is comfortable, I am already in and I do not have to log in again to another space."

The only weak point to have emerged is dispersion. This happens when information travels quickly and the tool structure allows temporary visualization. In Facebook the newest or most recently commented on are shown as the first posts, this increases the risk of losing older posts. To address this need, for example, it's a good idea to use the "File" tool in the Facebook groups to organize information so that the relevant ones are always visible and accessible.

Another instrument which is little used is the "search group" that lets you find older information.

\subsection{Facebook space between professional utility and learning}

Interviews show that both the "Orizzonte Scuola" and "La Scuola che Funziona" Facebook spaces are useful for professional purposes because in them, often with their own specifications, news and information about the world of education can be found such as:

- conferences and seminars;

- political, educational legislation and strikes;

- italian qualifications and competitions for teachers;

- $\quad$ sharing ideas and opinions among members.

These are relevant issues because they allow you to keep up-to-date, which is a real must in a context where the pace of the ageing medium of knowledge is moving very fast.

One of the added values most often mentioned by those interviewed is that one's own Facebook home page is updated by news and information from education world. It is important since, as this person said: "It is convenient, because it allows me not to waste time searching for information on the Web". This and other statements, however, require reflection: is it laziness, lack of time or difficulty that hinder finding information on the Web? Information retrieval on the web is one of the indicators for digital competence development [21] already mentioned by the European Parliament, which has been included since 2006 in the framework of the core competencies of citizenship, but knowing how to do it without wanting to and trusting only news filtered by social networks can be very dangerous (who can assure me that the link contains the only information I need for that topic?) and to some extent it subtracts one from responsibility.

Moving the speech from professional utility space to that of learning, almost all of those interviewed stressed a feeling of not having learned anything on Facebook: "Communications are fast, it is useful for the profession, but it's hard to say that I have learned." One reason is that Facebook is used during breaks, even with access by mobile, when people don't have time to stop and reflect, but only want to recover information filtering posts on their own Facebook home page, as well expressed by this interviewee: "It is not possible to learn on Facebook because it is used in downtime. For example, I mostly see my Facebook wall on the train with my smartphone after a day at work and filter posts to find one that interests me."

The attention depends on the use, in fact it appears that for some interviewed the unexpected moments of learning were when someone incited them to self-develop: for example, in Facebook they have learned when decided to deepen a topic that seems interesting (maybe from a link in a post).

\section{The communication analysis}

To complement the qualitative research, which has seen the participation of the founders of online 
environments and some members of the Facebook spaces, a quantitative analysis was carried out on a sample of 100 posts on the walls of "Orizzonte Scuola" Page (50) and "La Scuola che Funziona" Group (50).

We also summarized with a descriptive analysis the structural characteristics which distinguish the two environments. They inevitably influence the ways of approaching and using them.

\subsection{The "Orizzonte Scuola" Page}

Since March 2012 Facebook pages have changed appearance by adopting Timeline, as has occurred gradually to personal profiles. In this way, the wall looks like a real diary, referred to by month and year by way of a menu on the right of the screen. The reading of the historical memory of the page has become easier.

The cover image, at the very top of the page, has been customized with the catchphrase "One click school". The profile picture is the historical "Orizzonte Scuola" website logo (see Figure 1).

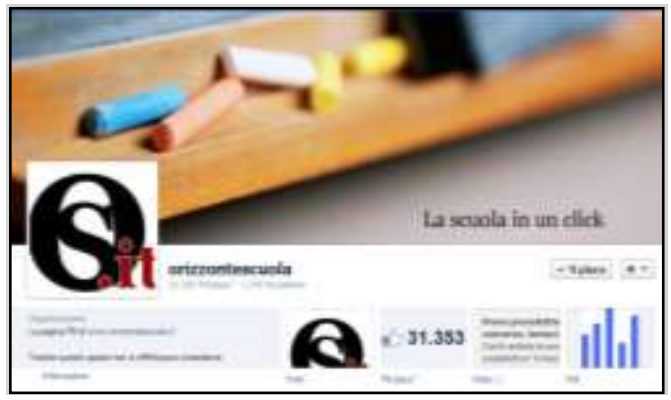

Figure 1. The "Orizzonte Scuola" Page

The function of sending messages to the administrator of the page has been disabled; moreover, in the page information it is specified that no expert advice is provided, which differs from original online space and home to the column "Ask Lalla", which is very popular and is the feather in the cap of the website.

Under the cover, we can see four tabs:

1. Photos. Publication is allowed for administrators only;

2. Likes. 31.353 (29 december 2012);

3. Notes;

4. Poll. App for surveys.

You can't view the fan page list, but the system informs us about who of our friends are "likers".

The default view called "Highlights" involves the separation of the posts entered by the administrator, which occupy most of the page and the box that collects recent posts posted by users. You can click the button below the tabs to switch to the display of all users' posts.

The posts by the administrator are entered daily and is viewable, through the "show shares" button, the number of shares made by the users, a practice that is widespread. The posts are mostly links directed to the home page of the site and the column "Ask Lalla".

There are also many comments posted by users; administrators take part in the conversation with accurate responses in case of questions or redirection to the forum portal, which is available without registration, but requires users to be logged in to take part in the discussions (you can register with your Facebook account data).

Noteworthy is the fact that no post submitted is always in view - the administrator could do this via the "Pin to top" function, which in the forum allows you to create the so-called sticky posts - neither has it been enlarged. Even the function that allows you to post events or milestones that emphasize the steps of "growth" of the page is not used.

In our analysis, we examined 50 posts submitted by users during the month of November 2012. The quota of messages was reached in two days in the period considered, the average therefore being 25 messages per day.

The authors are 8 men and 35 women displayed with their first and last name and in most cases with a referential image, which is in keeping with a strategy of «identity performance» [20]; it is not possible to identify the gender of the author of 2 of the messages, as they were inserted by a page administrator.

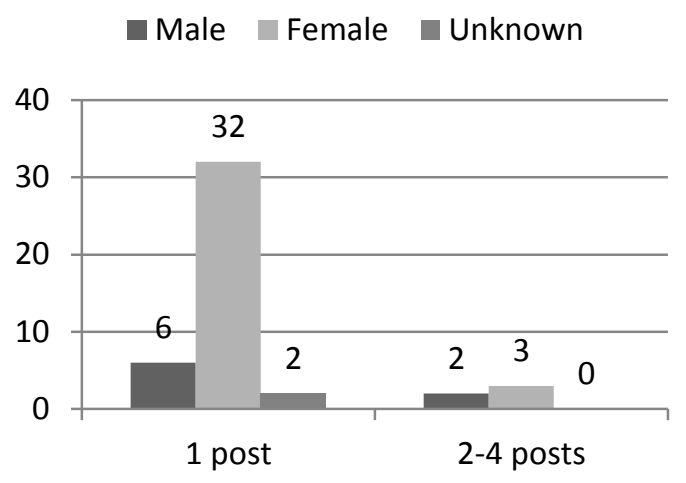

Figure 2. Number of posts per user

The bar graph shows the distribution of the 43 authors, by gender and number of posts entered (see Figure 2). In clear dominance are females, so they are also the main authors of single posts; only 5 people leave more than one message on the wall, usually single posts, in this case questions.

The messages are mostly on topic (see Figure 3). There is no explicit netiquette and publishing posts and comments is not subject to preventive moderation. 


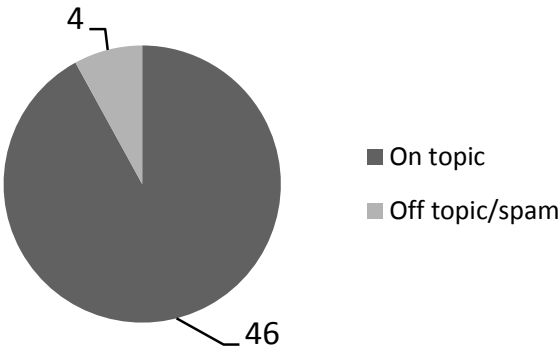

Figure 3. Number of on\&off topic posts

We categorized the message typology into simple posts, links and images. The last category actually, in the case of "Orizzonte Scuola", has not been detected, as the option of uploading images by users has been disabled. In addition, nobody in the post sample tags their friends.

As shown in the pie chart (see Figure 4), on the basis of 50 examined posts, there are 8 links included, among these, almost half are spam. The remaining 42 posts are simple and are all on topic, except 1.

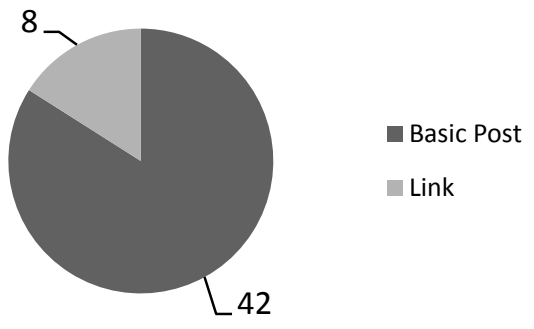

\section{Figure 4. Number of posts per category}

We initially distinguished the basic posts into information/statements and questions, in order to make evident the relationship between giving and taking, between "supply\&demand". The chart (see Figure 5) shows that the demand clearly exceeds the supply; specifically, the help requests concert the pre-selection test in a competitive exam for teachers, which was held in mid-December (difficulty with the online simulator, collaboration request for resolution of some questions, operating methods...). We can therefore understand the consistency of demands in relation to this truly felt subject.

The information posted is also related to almost all the pre-selection tests in the competition exam.

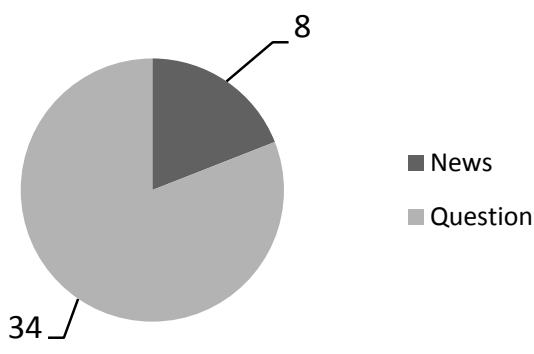

\section{Figure 5. Number of basic posts per sub- category}

The analysis continued to take into consideration the number of comments on the 50 posts: 139 comments were counted, with an average of 2.8 comments per post (the post with the most comments has 21). Two comments were made by the administrator of the page. Only 10 posts are without comments; 8 of which do not even receive the appreciation with the "like" button.

Wanting to highlight the relationship between the absence of comments or likes and relevance of the messages, you may notice that the 4 off topic/spam posts don't receive any and are therefore ignored.

Regarding the 34 posts with questions or help requests, it was noticed that 8 of the users who asked the questions then do not give feedback of any kind to the answers provided (thanks, further reflections...), which are almost entirely accurate and complete.

Two final remarks: maybe - due to what emerged from the interviews the Facebook wall doesn't facilitate the findings of one's own post in the constant stream of messages, despite the fact that the notification function should serve to focus attention where needed. The ease in which you can enter your post on the page is disarming, easy enough to run the risk of deeming it granted that there will always be someone connected and able to come to your rescue. It is known that there is a certain number of users during the period considered who often commented in great detail on the posts inserted. In all likelihood, these are the most devoted users and experts: the ones who frequent the "Orizzonte Scuola" page more naturally.

\subsection{The "La Scuola che Funziona" Group}

The groups at the beginning of the year 2012, were also subjected to a makeover, not just aesthetically.

Instead of the simple title at the top of the page at the opening of the group, you see a photo mosaic. These are the avatars of friends who, like us, are members of the group. Each photo is clickable and sends you back to personal walls (see Figure 6). 


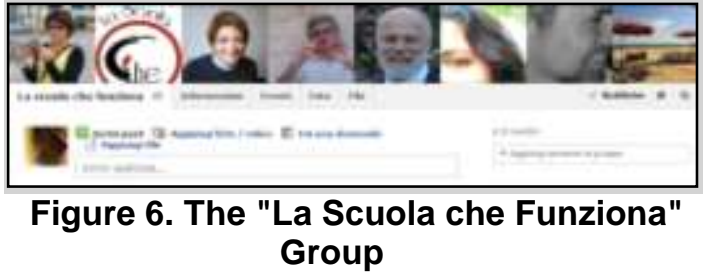

Below the images, in the "About" tab you can view the information of the group: "point of connection with Ning network"; past events (3) (is also active on the button "Create event"); photos uploaded (50), with the possibility of loading new ones, in addition to videos; then the collection of shared files, that can be created from scratch by the group or can be uploaded from the computer. This last feature, in this group has not been exploited; it may be very useful for example for creating FAQs, negotiated netiquette or a collection of links related to a specific theme. Files can be edited by all the group members.

Privacy is set to "open", so all Facebook users can find the group, read the wall and access the member list. To post you need to be, however, a member of the group (610 registered members at 29 December 2012).

What is interesting is the option that allows the user to receive notifications, only on Facebook, or via e-mail whenever a new message is posted; you can also follow individual posts in order to be informed of any new comments added.

A clarification is necessary: unlike the Facebook Pages, it is not possible on the group wall to distinguish the posts of the administrators from those by members without privileges. The message flow is visually continuous and navigation is permitted only with the vertical scroll, without shortcuts offered by Timeline. The search function comes in handy, permitting information recovery for both user name and keyword.

We considered 50 user posts, between October and November 2012. The quota of messages was reached in 27 days: the average is therefore 1.9 messages per day.

The authors are 8 men and 16 women displayed with first and last name and in most cases with a passport size photo or tranche-de-vie [20]; it is not possible to determine the gender of the author of 2 messages, as they were inserted by a page administrator. These are the same as those posted on the "Orizzonte Scuola" wall and are clearly spam.

In the group you can tag members, even if they are not mutual friends; 2 tags are detected in the sample of posts considered.

Figure 7 shows the distribution of the 29 users for gender and number of posts inserted. As for "Orizzonte Scuola", there are more female than male authors; 8 people leave more than one message on the wall page, of which one is the original founder of the Ning social network, as well as group administrator.

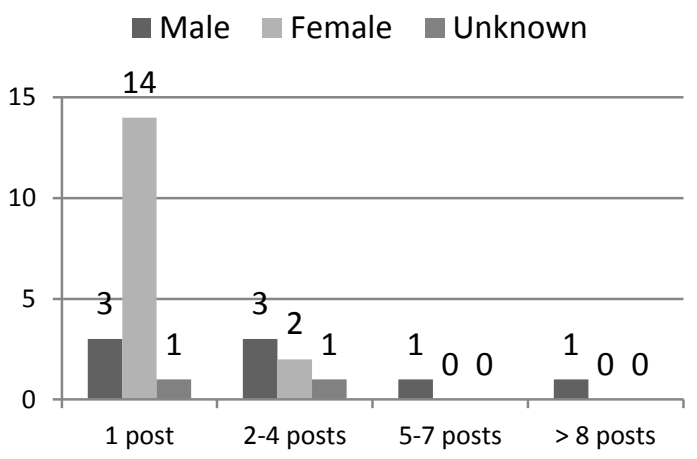

Figure 7. Number of posts per user

The messages are mostly on topic (see Figure 8).

There is no explicit netiquette and publishing posts and comments is not subject to preventive moderation, as the telephone interview with the administrator confirmed.

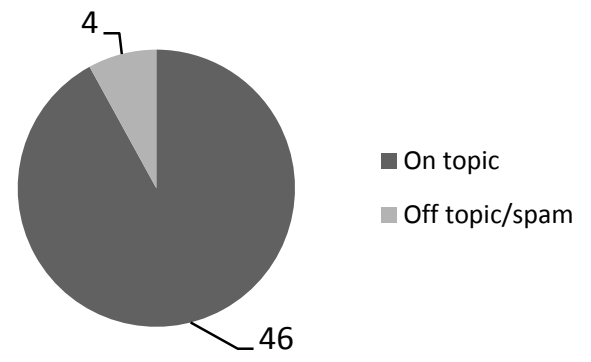

Figure 8. Number of on\&off topic posts

We recorded mostly various kinds of link sharing (see Figure 9). There are 40 links, 7 basic posts and 3 images. Just one post contains a question/help request, not on a specific topic but on a technical issue related to the use of the group.

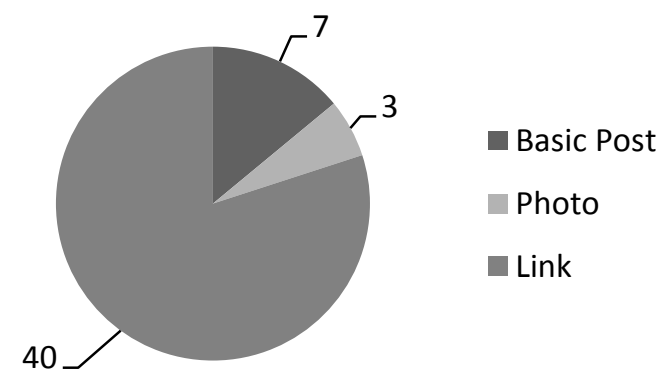

Figure 9. Number of posts per category

Further detailing the types of links, it was possible to photograph a complex framework of resources (see Figure 10): links to news, personal blogs or other users predominate. The topics are 
varied: school policies, education and new technologies, ideas and provocations on the figure of the teacher.

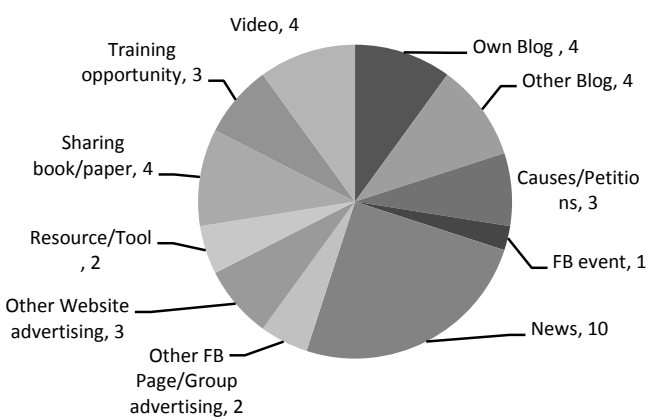

\section{Figure 5. Number of links per sub-category}

The analysis continued to take into consideration the number of comments on the 50 posts: 65 comments were counted, with an average of 1,3 comments per post (the post with the most comments has 17). 36 posts are without any comments; 18 of which do not even receive appreciation with the "like" button.

Comparing these data with the findings of the interviews, we believe that most of the members act as lurkers, reading without leaving any trace; maybe the group is considered as a point of departure for further outside research or an aggregator of resources to choose from that fit the need of the hour. Among other things, in this group, the "Seen by" function is not yet activated. This allows the user to see the list of those who have read the individual posts.

The most active users, primarily the ones who manage the page, are on two fronts: publishing new posts and commenting. It is understood that the relationship between "supply\&demand" is more balanced than it is on "Orizzonte Scuola", perhaps because of the lower number of active users.

\section{Conclusion}

Literature recognizes that some of the most important scientific discoveries are born thanks to unexpected moments that lead to profound insights, changing perspectives and assumptions [22] [23]. Making fortunate discoveries by accident is a condition known as «serendipity» [24]. For several years the possibility of facilitating and evaluating the effects of accidental discovery on the Web, together with the recognition of the latter as «the greatest serendipity engine in the history of culture» [25], are being explored by academics [26] [27].

As we have already noted [6], in this second research phase, interviews reveal that a very small number of teachers defined what took place within the Facebook spaces "Orizzonte Scuola" and "La Scuola che Funziona" as learning and what happened was rather a boost to self-training, starting with large individual motivation. On the other hand, informal learning can be developed if the individual moves in reflection and conceptualization [28], that if you have time to reflect and recognize that what you have before your eyes may be of interest. It is adequate to deem incalculable the number of posts that each day invade our Facebook homepage and how much time we devote to reading them, also to understand first, the identification of the post that you are interested in and second, that the requirement of recognition and reflection are not so obvious. Hypothetically, navigation through the communication flow of social networks can lead to the unexpected discovery of relevant and significant information or triggering chains to other relevant information, for example, by following links on topics of interest [9]. The individual though, must be ready to receive and recognize this information, if not, then it cannot be verified as learning. However, learning is not simply an object of pure chance, it is influenced by personal goals, interests and previous knowledge [24]. Unlike the traditional way of internet surfing, involvement in social networks makes possible the direct interaction with users that generate these items of information, increasing the chance of mutual exploration and expanding the experience of social learning and agreed subject inclination.

Our data walls analysis of the two on line spaces show that, at least for the time period considered, in "La Scuola che Funziona" there is little exchange of communication within. Users often publish posts, but many of them do not follow or receive comments, while in "Orizzonte Scuola" users ask many questions and receive just in time that help needed from members.

Even the expansion of its social network does not seem to be an important objective. This is partially present in "La Scuola che Funziona" group, while no explicit goal is revealed for the "Orizzonte Scuola" users.

In our case study both the interviews and wall communication analysis reveal that as well as learning and expansion of one's own social network one can talk about information retrieval - information that is often not searched for, but received on the Facebook home page. Other than information retrieval, there is «information expectation»: news and request answers that people somehow expect from the online space, as in almost expecting information purely for being enrolled in that group and/or page, often without making any contribution. As a result, those writing and posting in networks are more or less the same users, which become a sort of "hard core" (using the words from an interview) and are acknowledged and referred to in this way by other users. 


\section{Acknowledgements}

The authors thank the administrators and members of the Facebook spaces, "Orizzonte Scuola" and "La Scuola che Funziona", for their invaluable cooperation.

\section{References}

[1] M. Sideri, "Facebook, il continente più giovane", Corriere della Sera, Milano, retrieved 30 december 2012, from: http://www.corriere.it/

[2] Censis, U.C.S.I., Decimo Rapporto sulla comunicazione. I media siamo noi. L'inizio dell'era biomediatica, FrancoAngeli, Milano, 2012.

[3] Marinelli, A., Connessioni, Guerini Studio, Milano, 2004.

[4] De Kerckhove, D., Brainframes. Mente, tecnologia, mercato, Baskerville, Bologna, 1993.

[5] R.E. Wilson, S.D. Gosling, L.T. Graham, "A review of Facebook research in the social sciences". Perspectives on Psychological Science, 7(3), 2012, pp. 203-220.

[6] L. Petti, S. Triacca, "Informal Learning and Teacher Training on the Web: User Perceptions of Two Italian Online Communities for Teachers" International Conference on Education, Infonomics Society, Ireland, 2012, pp. 30-34.

[7] Guskey, T.R., Huberman, M., Introduction, in Guskey, T.R., Huberman, M., Professional development in education: new paradigms and practice, Teacher College Press, New York, 1995.

[8] Drucker, P.F., Post-capitalist society, Butterworth Heinemann, Oxford, 1993.

[9] L.M. Conner, "Informal Learning." Ageless Learner, 1997-2005, retrieved 30 december 2012 from: http://marciaconner.com/resources/informal-learning/

[10] Castells, M., La nascita della società in rete, EgeaUniversità Bocconi Editore, Milano, 2002.

[11] B. Wellman, "Computer Networks As Social Networks", Science, (293), 2001 pp. 2031-2034; retrieved 30 december from: http://homes.chass.utoronto.ca/ wellman

[12] D. Boyd, N. Ellison, "Social Network Sites: Definition, History, and Scholarship", Journal of Computer-Mediated Communication, 13(1), article 11, 2007, pp. 210-230.

[13] Wenger E. C., Communities of Practice. Learning, Meaning, and Identity, Cambridge University Press, New York, 2008.

[14] M. Ranieri, S. Manca, A. Fini, "Promuovere comunità professionali di insegnanti e professionisti attraverso i siti di Social Network", TD Tecnologie Didattiche, 20 (1), 2012, pp. 24-30.

[15] Anderson, G., Fundamentals of Education Research, The Falmer Press, London, 1990.

[16] Viganò, R., Pedagogia e sperimentazione. Metodi e strumenti per la ricerca educativa, Vita e Pensiero, Milano, 2002.

[17] Mantovani, S., (Ed.) La ricerca sul campo in educazione. I metodi qualitativi, Bruno Mondadori, Milano, 1998.

[18] Petti, L., Apprendimento informale in Rete. Dalla progettazione al mantenimento delle comunità on line, Franco Angeli, Milano, 2011.

[19] Rivoltella, P.C., Ferrari, S. (Ed.), A scuola con i media digitali. Problemi, didattiche, strumenti, Vita e Pensiero, Milano, 2010.

[20] Rivoltella, P.C., Il volto sociale di Facebook. Rappresentazione e costruzione identitaria nella società estroflessa, in Vinci D. (Ed), Il volto nel pensiero contemporaneo, Il pozzo di Giacobbe, Trapani, 2010, p. 504-518.

[21] Buckingham, D., Media Education. Alfabetizzazione, apprendimento e cultura contemporanea, Erickson, Trento, 2006

[22] Kuhn, T., The structure of scientific revolutions, University of Chicago Press, Chicago, 1962.

[23] Mezirow, J., Transformative dimensions of adult learning, Jossey-Bass, San Francisco, 1991.

[24] G. Fine, J. Deegan, "Three Principles of Serendip: Insight, Chance and Discovery in Qualitative Research", International Journal of Qualitative Studies in Education, 9, 1996, pp. 434-447.

[25] S., Johnson, "Can We Please Kill This Meme Now", 2006; retrieved 30 december 2012 from: http://www.stevenberlinjohnson.com/2006/05/can_we_ple ase_k.html

[26] N. Eagle, A. Pentland, "Social Serendipity: Proximity Sensing and Cueing", MIT Technical report, 2004, retrieved 30 december 2012 from: http://vismod.media.mit.edu//tech-reports/TR-580.pdf

[27] M. Bernstein, S. Kairam, B. Suh, L. Hong and E.H. Chi, "A torrent of tweets: managing information overload in online social streams", CHI 2010 Workshop on Microblogging, Atlanta, GA. ACM, 20 October 2010, retrieved $\quad 30$ december 2012 from: http://www.parc.com/content/attachments/torrent-oftweets.pdf 